\title{
Caracterização morfométrica e efeitos ecotoxicológicos do chumbo na germinação de sementes de Schinus terebinthifolius Raddi
}

\author{
Morphometric characterization and ecotoxicological effect of lead in seed \\ germination of Schinus terebinthifolius Raddi
}

\author{
Edevaldo Silva1*, Maria de Fátima Guilherme', Habyhabanne Oliveira', Zenira Viana², \\ Vera Lúcia Santos²
}

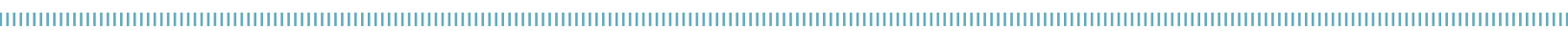

RESUMO: Schinus terebinthifolius Raddi é uma árvore perenifólia, encontrada em diversos biomas brasileiros e utilizada no reflorestamento de áreas degradadas que podem estar contaminadas por metais pesados. Esta pesquisa determinou as características morfométricas e avaliou os efeitos ecotoxicológicos do chumbo $(\mathrm{Pb})$ no desenvolvimento germinativo da aroeira pimenteira $(S$. terebinthifolius). Foram determinadas a umidade (\%) e 12 medidas morfométricas das sementes $(\mathrm{n}=230)$, a saber: peso de 1.000 sementes, comprimento, largura, espessura, alongamento em 3 dimensões (comprimento, largura e espessura), diâmetro médio geométrico, área superficial, volume, esfericidade e densidade volumétrica. Os efeitos ecotoxicológicos do $\mathrm{Pb}$ foram avaliados em 8 diferentes concentraçóes $(0,2 ; 0,4 ; 0,6 ; 0,8 ; 1,0 ; 2,0 ; 4,0$ e $6,0 \mathrm{mM})$ em triplicatas com 40 sementes por replicata. As variáveis resposta foram: volume da semente durante o desenvolvimento germinativo, porcentagem de germinação e velocidade de germinação. $\mathrm{O} \mathrm{Pb}$ presente em baixas concentraçôes causa efeitos tóxicos que afetam o percentual $(0,2 \mathrm{mM})$ e a velocidade de germinação $(0,4 \mathrm{mM})$. Apesar desses efeitos, eles não se elevaram quando a $S$. terebinthifolius foi exposta a concentraçóes maiores de $\mathrm{Pb}$. Assim, é provável que a $S$. terebinthifolius tenha tolerância ou adaptaçáo fisiológica ao $\mathrm{Pb}$. Entretanto, em ambientes contaminados por esse metal, o seu estabelecimento inicial pode ser comprometido ou impossibilitado devido a esse estresse químico.

PALAVRAS-CHAVE: biometria; contaminação; metal pesado.

\begin{abstract}
Schinus terebinthifolius Raddi is an evergreen tree found in several Brazilian biomes and used in the reforestation of degraded areas that may be contaminated by heavy metals. This research determined the morphometric characteristics and evaluated the ecotoxicological effects of lead $(\mathrm{Pb})$ in the germinal development of pepper mastic ( $S$. terebinthifolius). The moisture (\%) and 12 morphometric measurements of seeds ( $\mathrm{n}=230)$ were determined: 1,000 seed weight, length, width, thickness, elongation in three dimensions (length, width and thickness), geometric mean diameter, surface area, volume, sphericity and bulk density. Ecotoxicological effects of lead on the germination of seed development were evaluated in eight different concentrations $(0.2,0.4,0.6,0.8,1.0,2.0,4.0$ and $6.0 \mathrm{mM}$ ) in triplicate with 40 seeds per replicate. The response variables were: volume of seed germination during development, germination percentage, mean germination time and germination speed index. $\mathrm{Pb}$ present in low concentrations causes toxic effects that affect the percentage $(0.2 \mathrm{mM})$ and germination speed index $(0.4 \mathrm{mM})$. Despite these effects, they did not increase when the $S$. terebinthifolius was exposed to higher concentrations of $\mathrm{Pb}$. Thus, it is likely that $S$. terebinthifolius have tolerance or physiological adaptation to $\mathrm{Pb}$. However, in $\mathrm{Pb}$ contaminated environments, its initial establishment may be compromised or made impossible, due to this chemical stress.
\end{abstract}

KEYWORDS: biometrics; contamination; heavy metal.

\footnotetext{
'Universidade Federal de Campina Grande - Patos (PB), Brasil.

${ }^{2}$ Universidade Federal da Bahia - Salvador (BA), Brasil.

*Autor correspondente: edevaldos@yahoo.com.br

Recebido em: 03/04/2016. Aceito em: 11/10/2017
} 


\section{INTRODUÇÃO}

S. terebinthifolius Raddi pertence à família Anacardiaceae, conhecida como pimenta brasileira, e apresenta ampla distribuição geográfica por todo o mundo (GOMES et al., 2013a). É uma árvore de tamanho médio (SANTANA et al., 2012), com folhas compostas por folíolos lanceolados e pontiagudos, numerosas flores, pequenas e brancas ou amarelo-esverdeadas, e seu fruto é drupa vermelha e lustrosa (OLIVEIRA JUNIOR et al., 2013).

É uma planta utilizada em recuperação de áreas degradadas e ciliares, devido a possuir caráter de espécie pioneira e agressiva, sendo dispersa por zoocoria (MORAIS et al., 2012). Todavia, o plantio de mudas é o mais difundido método para recuperação de áreas degradadas, sendo mais recomendado o uso tanto de espécies pioneiras quanto espécies clímax (GOMES et al., 2013b).

S. terebinthifolius possui diversas utilidades, tanto madeireiras quanto energéticas e medicinais, pois é uma espécie que pode ser utilizada como fonte principal de extrativismo para uso dos frutos e sementes na forma de pimenta rosa (GOMES et al., 2013b).

A germinação envolve processos iniciais do desenvolvimento da planta (SILVA et al., 2014) e a caracterização biométrica para avaliar os caracteres morfológicos da planta é importante para a uniformização de emergência das plântulas, promovendo a obtenção de mudas de melhor vigor (SILVA et al., 2017a).

Estudos sobre a germinação de sementes são fundamentais para ampliar os conhecimentos sobre a influência dos fatores ambientais no desenvolvimento morfofisiológico do embriáo e da plântula (GORDIN et al., 2012).

$\mathrm{O}$ chumbo $(\mathrm{Pb})$ é considerado, na lista da Agência de Proteção Ambiental dos Estados Unidos, como um dos metais pesados mais ameaçadores (ATSDR, 2008), sendo potencialmente tóxico, provocando danos ao desenvolvimento das plantas (SILVA et al. 2015) e com tendência a se acumular no solo.

As plantas cultivadas em ambientes com concentração desse metal podem ter o seu crescimento e desenvolvimento radicular afetado, o qual possibilita a avaliação do grau de tolerância ou sensibilidade do $\mathrm{Pb}$ por diferentes espécies (SOUZA et al., 2011). Os efeitos tóxicos do $\mathrm{Pb}$ podem ser observados no crescimento das mudas, na inibição da germinação, na redução do crescimento das raízes, na redução da produção de biomassa vegetal, bem como nas alteraçóes no metabolismo da planta (MISHRA; CHOUDHURI, 1998; SHARMA; DUBEY, 2005; BORGES et al., 2016).

A técnica de fitorremediaçáo tem sido indicada como uma maneira de restaurar locais contaminados por metais pesados, utilizando espécies de plantas tolerantes para a remoção desses poluentes do solo (RIBEIRO et al., 2015). Para que essa técnica seja possível, é preciso identificar plantas hiperacumuladoras, necessitando de mais estudos fisiológicos e morfológicos (PEREIRA, 2010).

Em geral, as espécies vegetais que toleram a exposição a concentraçôes significativas de metais possuem poucos efeitos inibitórios em seu desenvolvimento germinativo e crescimento inicial. A S. terebinthifolius Raddi utilizada em uma determinada área poluída com altas concentraçóes de $\mathrm{Pb}$ pode ter limitaçóes para estabelecimento de suas geraçóes futuras, que serão desenvolvidas naturalmente pela dispersão e germinação de suas sementes no solo degradado.

O objetivo desta pesquisa foi avaliar as características morfométricas e os efeitos ecotoxicológicos do $\mathrm{Pb}$ no desenvolvimento germinativo da aroeira pimenteira (S. terebinthifolius).

\section{MATERIAL E MÉTODOS}

As sementes de $S$. terebinthifolius Raddi, provenientes da colheita de 2012, foram adquiridas no Instituto de Pesquisas e Estudos Florestais (IPEF, Piracicaba, São Paulo).

O peso de mil sementes foi determinado a partir da contagem de oito subamostras de cem sementes selecionadas ao acaso, expresso em gramas (g), conforme BRASIL, (2009). A umidade (\%) foi determinada pelo método da estufa a $105 \pm 3^{\circ} \mathrm{C}$ por 24 horas (BRASIL, 2009), com 2 repetiçóes de sementes inteiras, em que os percentuais de umidade foram calculados em base seca.

As medidas de comprimento, largura e espessura das sementes $(n=230)$ foram aferidas com o auxílio de um paquímetro digital $(0,01 \mathrm{~mm})$. O diâmetro médio geométrico (DMG) foi calculado segundo SAHAY; SINGH (2004). Enquanto o alongamento das sementes em três orientaçóes (comprimento, largura e espessura) foi determinado segundo método de FIRATLIGIL-DURMUS et al. (2010). O DMG e o alongamento foram expressos em milímetros ( $\mathrm{mm})$.

As medidas de área superficial $\left(\mathrm{em} \mathrm{mm}^{2}\right)$ e volume (em $\mathrm{mm}^{3}$ ) das sementes foram determinadas segundo equaçóes de MCCABE et al. (1993). A esfericidade (em \%) foi calculada utilizando os valores do DMG e do comprimento das sementes, segundo método proposto por MOHSENIN (1983).

A densidade volumétrica foi quantificada pela relação massa/ volume, pela média das massas (10 repetições) de sementes necessárias para preencher um volume de $25 \mathrm{~mL}$. Os resultados foram convertidos e expressos em kg. $\mathrm{m}^{-3}$.

No teste de germinação, as sementes foram previamente desinfetadas em solução de hipoclorito de sódio $(\mathrm{NaClO}$ $2,5 \%$ ) por 10 minutos. Foram utilizadas 200 sementes, com 4 repetiçóes de 50 sementes semeadas em placas de Petri com camada dupla de papel de germinação esterilizado e umedecido com $11 \mathrm{~mL}$ de água destilada. 
O teste de embebição foi realizado simultaneamente ao teste de germinação, pela quantificação diária, durante 16 dias, da variaçáo das medidas de comprimento, largura, espessura e massa das sementes semeadas. O resultado desse teste foi analisado a partir da variação do volume das sementes e da quantificação indireta do volume de água consumida.

Para a avaliação dos efeitos ecotoxicológicos do $\mathrm{Pb}$ no desenvolvimento germinativo de sementes de S. terebinthifolius, as sementes foram imersas, por 30 minutos, em $20 \mathrm{~mL}$ das respectivas concentraçóes experimentais de $\mathrm{Pb}$. As sementes foram semeadas em placas de Petri $(150 \mathrm{~mm}$ de diâmetro) para germinação em camada dupla de papel de germinação.

O papel de semeadura foi embebido em soluçáo em 8 concentraçōes $(0,2 ; 0,4 ; 0,6 ; 0,8 ; 1,0 ; 2,0 ; 4,0$ e $6,0 \mathrm{mM})$ em triplicatas com 40 sementes em cada replicata. $\mathrm{O}$ pH das soluçôes e da água destilada utilizada no experimento controle foi de cerca de 6,0. A placa de Petri contendo apenas água deionizada para embebiçáo do papel foi usada para controle da variância.

O teste de embebição foi repetitivo para os experimentos, para verificar possíveis efeitos no aumento do volume das sementes no período que precede a emergência da radícula.

A porcentagem de germinação e o índice de velocidade de germinação (IVG) foram quantificados segundo MAGUIRE (1962). As alteraçôes dos parâmetros morfológicos (comprimento, largura, espessura e medidas de partes aéreas e da raiz das plântulas) e de volume de água de crescimento foram observadas diariamente durante todo o período do experimento (30 dias).

Os estudos laboratoriais foram conduzidos sob condições controladas, em que todas as placas com as sementes foram mantidas na temperatura de $30 \pm 2{ }^{\circ} \mathrm{C}$ e com fotoperíodo de 16 horas de luz e 8 horas de escuro.

As análises estatísticas dos resultados das medidas foram realizadas no software estatístico SPSS 20.0. Quando necessário, os dados foram transformados em $\operatorname{arcsen}[(\mathrm{x}+0,5) / 100]^{0,5}$ para garantir a sua homocedasticidade, que foram avaliados por meio da análise de variância (ANOVA) seguida do teste de Tukey para determinar significância estatística da diferença entre as variâncias. A análise do crescimento das partes da plântula, ao longo do tempo, foi realizada por meio do modelo de regressão linear polinomial. Para todas as análises estatísticas, foi considerado o nível de significância com $\mathrm{p}<0,05$.

\section{RESULTADOS}

Os valores médios das diversas medidas morfométricas das sementes de $S$. terebinthifolius estão descritos na Tabela 1. Observou-se baixa variância na maioria das medidas, indicando homogeneidade da amostra quanto aos seus aspectos morfométricos. As sementes apresentaram peso médio de 1.000 sementes de 30,90 g; 6,13\% de umidade (em base seca); e densidade volumétrica média de 1,73 $\pm 0,14\left(\mathrm{~g} \cdot \mathrm{cm}^{-3}\right)$. Suas medidas dimensionais (comprimento, largura e espessura) apresentaram maiores valores (em mm) para o comprimento $(4,22 \pm 0,24)$ e a largura $(3,55 \pm 0,25)$, o que confere menor alongamento na orientaçáo do comprimento $(E c=1,19 \pm 0,09)$ e alta esfericidade $(74,33 \%)$.

Os histogramas de frequência para as medidas (em mm) de comprimento, largura e espessura das sementes (Fig. 1) demonstram que a maior parte das sementes de S. terebinthifolius apresentou faixa de comprimento entre 4,04 e 4,31 $\mathrm{mm}$. Para a largura e a espessura, as faixas de medidas mais frequentes foram 3,28-3,72 e 1,97-2,20 mm, respectivamente.

Os resultados do teste de embebiçáo estão descritos na Fig. 2. Houve elevado aumento do volume das sementes no período anterior à sua germinação (entre o primeiro e o quinto dia), a partir do sexto dia (dia de emergência da radícula: germinação) se observou redução gradual do volume das sementes. A correlação entre a variação volumétrica e os dias de desenvolvimento germinativo é melhor explicada pelo modelo de regressão polinomial, apresentando valor de $\mathrm{R}^{2}=0,858$.

Tabela 1. Valores morfométricos, percentual de germinação e velocidade de germinação das sementes de Schinus terebinthifolius $(n=230)$.

\begin{tabular}{|c|c|c|c|}
\hline Parâmetro & Média \pm DP & Mín - Máx & CV (\%) \\
\hline $\begin{array}{l}\text { Peso de } 1.000 \\
\text { sementes }(\mathrm{g})\end{array}$ & $30,90 \pm 3,09$ & $24,91-36,92$ & 10,02 \\
\hline $\begin{array}{l}\text { Umidade (\%, em } \\
\text { base seca) }\end{array}$ & $6,13 \pm 0,23$ & $5,87-6,32$ & 3,82 \\
\hline Densidade $\left(\mathrm{g} \mathrm{cm}^{-3}\right)$ & $1,73 \pm 0,14$ & $1,71-1,75$ & 0,80 \\
\hline Comprimento $(\mathrm{mm})$ & $4,22 \pm 0,24$ & $3,62-4,72$ & 5,58 \\
\hline Largura (mm) & $3,55 \pm 0,25$ & $2,98-4,16$ & 7,11 \\
\hline Espessura (mm) & $2,06 \pm 0,18$ & $1,61-2,50$ & 8,89 \\
\hline DMG (mm) & $3,13 \pm 0,16$ & $2,82-3,43$ & 5,02 \\
\hline $\mathrm{E}$ - Vertical (mm) & $1,73 \pm 0,19$ & $1,36-2,30$ & 10,98 \\
\hline $\begin{array}{l}\text { E - Comprimento } \\
(\mathrm{mm})\end{array}$ & $1,19 \pm 0,09$ & $1,01-1,40$ & 7,19 \\
\hline E - Espessura (mm) & $2,06 \pm 0,21$ & $1,63-2,67$ & 10,12 \\
\hline $\begin{array}{l}\text { Área superficial } \\
\left(\mathrm{mm}^{2}\right)\end{array}$ & $30,90 \pm 3,09$ & $24,91-36,92$ & 10,00 \\
\hline Volume $\left(\mathrm{mm}^{3}\right)$ & $16,21 \pm 2,42$ & $11,69-21,10$ & 14,94 \\
\hline Esfericidade & $74,30 \pm 3,33$ & $65,18-81,69$ & 4,48 \\
\hline Germinação (\%) & $39,78 \pm 10,34$ & $29,32-49,92$ & 26,00 \\
\hline IVG & $0,45 \pm 0,12$ & $0,31-0,56$ & 15,46 \\
\hline
\end{tabular}

DP: desvio padrão; CV: coeficiente de variação; DMG: diâmetro médio geométrico; E: alongamento; IVG: índice de velocidade de germinação. 
O consumo de água diário foi melhor interpretado por meio do modelo linear de regressão $(y=0,5148 x-0,3782$; $\mathrm{R}^{2}=0,984$ ), apresentando consumo médio diário de $12,87 \mu \mathrm{L}$ de água por semente.

No caso da germinação da $S$. terebinthifolius, a preocupação com o consumo de água durante o processo germinativo é maior devido às sementes necessitarem de 10 a 30 dias para que se processe a emergência da radícula e o desenvolvimento da plântula.

A avaliação do efeito no volume das sementes da S. terebinthifolius durante o desenvolvimento germinativo está
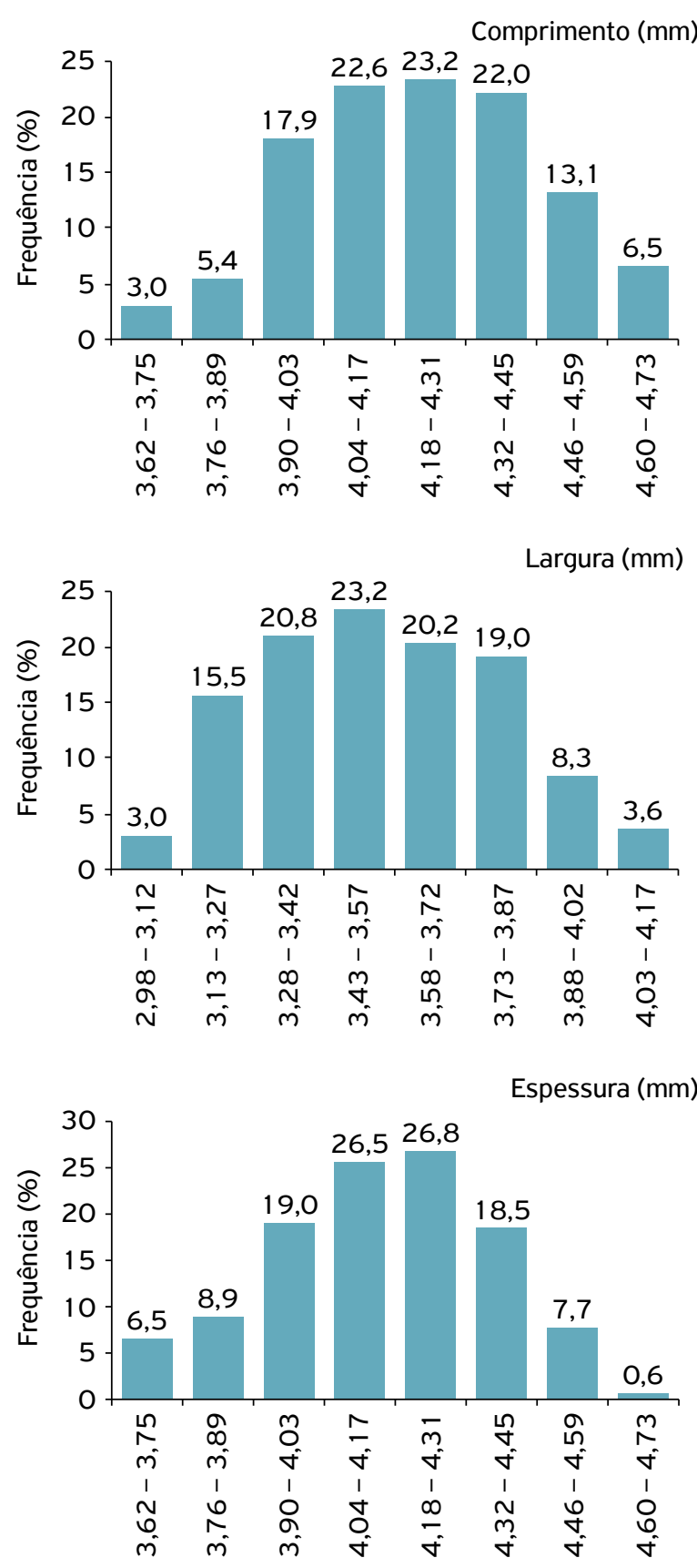

Figura 1. Histogramas das frequências do comprimento, largura e espessura (em $\mathrm{mm}$ ) das sementes de Schinus terebinthifolius $(n=230)$. descrita na Fig. 3. Não houve variação significativa $(\mathrm{p}<0,001)$ do volume das sementes entre as diferentes concentrações e o tratamento controle.

$\mathrm{O} \mathrm{Pb}$ interferiu significativamente no percentual de germinação $(\mathrm{G} \%)$ a partir de $0,2 \mathrm{mM}$, entretanto, o $\mathrm{G} \%$ náo apresentou correlação significativa com o aumento da concentração de $\mathrm{Pb}$ (Fig. 4). O potencial inibitório variou entre $30,9 \%(6,0 \mathrm{mM})$ e $61,1 \%(0,6 \mathrm{mM})$ em relação ao controle.

Os resultados do IVG reportaram que concentração de $\mathrm{Pb}$ influencia na redução da velocidade de germinação da S. terebinthifolius a partir de 0,4 $\mathrm{mM}$ (Fig. 5), com valor de IVG $(0,26)$ cerca de $42,2 \%$ menor que o controle $(0,45)$. A sua inibição máxima foi de 1,0 mM, com IVG igual a 0,14 e inibição de cerca de $68,9 \%$.

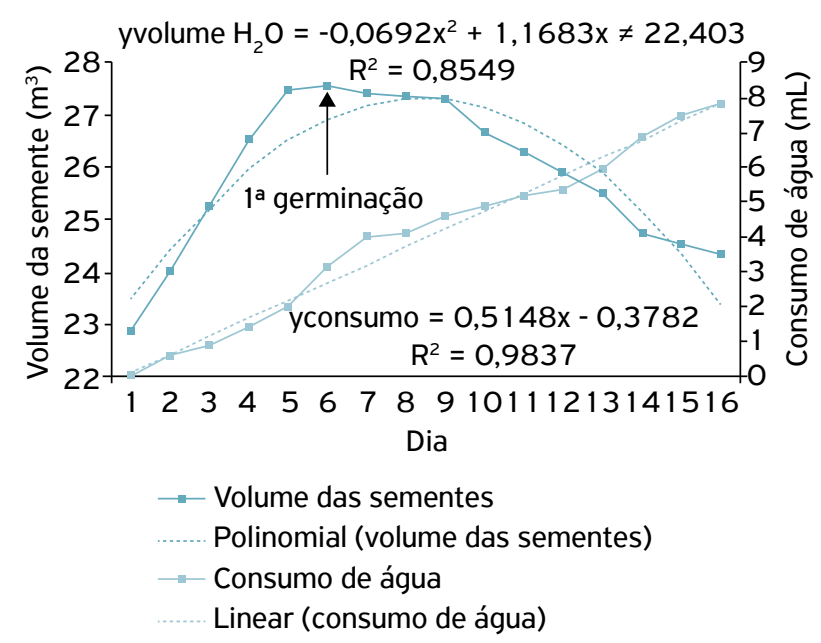

Figura 2. Teste de embebição e volume das sementes de Schinus terebinthifolius durante o seu desenvolvimento germinativo.

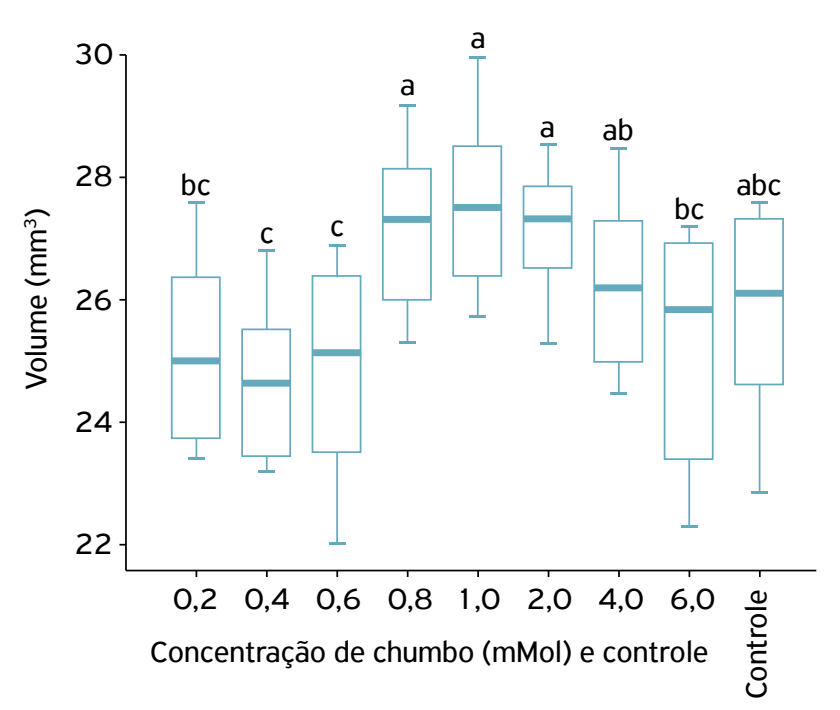

Figura 3. Avaliação do efeito do chumbo no volume das sementes de Schinus terebinthifolius durante o desenvolvimento germinativo. 


\section{DISCUSSÃO}

As análises morfométricas são importantes para verificar possíveis variaçôes fenotípicas em indivíduos de mesma espécie. Assim, as variações morfométricas podem estar relacionadas aos fatores genéticos, e esse aspecto é importante para estudos de melhoramento genético da espécie (SILVA et al., 2017b).

Os estudos sobre as espécies florestais utilizadas em recomposiçáo florestal, de uma maneira geral, são escassos (NASCIMENTO et al., 2012) e a análise morfométrica para o S. terebinthifolius tem sido pouco reportada na literatura.

SOUZA et al. (2013), avaliando a morfometria e a viabilidade de sementes de $S$. terebinthifolius em três diferentes regiōes (Brejo Grande; Neópolis e Propriá) da regiāo do Baixo São Francisco Sergipano, encontraram as seguintes faixas de medidas morfométricas: comprimento $(3,33-4,02 \mathrm{~mm})$; largura $(2,89-3,37 \mathrm{~mm})$; e espessura $(1,58-2,07 \mathrm{~mm})$.

A umidade das sementes de $S$. terebinthifolius reportada na literatura tem grande faixa de variaçáo: 11,9 a 13,2\%

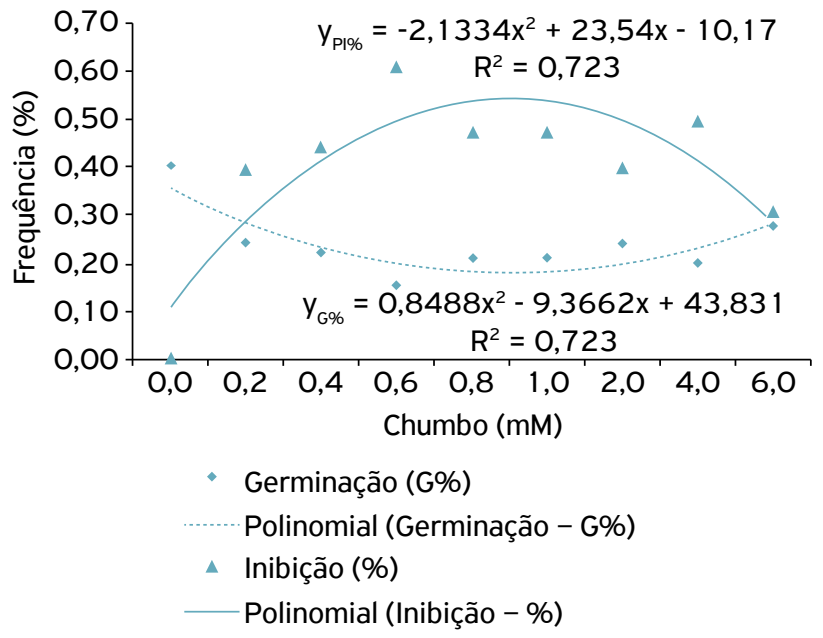

Figura 4. Percentual de germinação e potencial inibitório do chumbo em sementes de Schinus terebinthifolius.

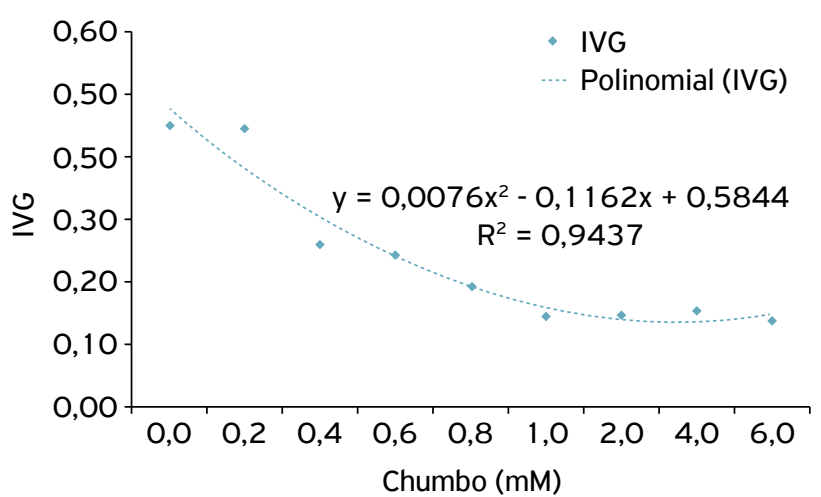

IVG: índice de velocidade de germinação.

Figura 5. Índice de velocidade de germinação do chumbo em sementes de Schinus terebinthifolius.
(PACHECO et al., 2011) e de 11,59 a 33,26\% (SOUZA et al., 2013).

O percentual de germinaçáo do experimento controle foi similar aos percentuais germinativos reportados por SOUZA et al. (2013) e PACHECO et al. (2011), que apresentaram valores percentuais muito variados para a germinação, encontrando, respectivamente, faixas de 4,0$83,0 \%$ e $38-74 \%$.

A S. terebinthifolius reduziu o seu G\% para outro metal pesado tóxico (cádmio) somente a $0,6 \mathrm{mM}$, mas apresentou tendência similar de manter constante o G\%, mesmo aumentando as concentraçôes do metal (SILVA et al., 2017a).

Foi observada maior variabilidade para os valores de IVG entre as pesquisas com a espécie de $S$. terebinthifolius. Os valores aqui reportados $(0,14-0,45)$ são similares aos de SOUZA et al. (2013), que encontraram IVG variando de 0,00 a 0,98 . O IVG encontrado por PACHECO et al. (2011) para a mesma espécie foi bem mais elevado $(2,5-4,63)$.

A contaminação ambiental por metais pesados pode tornar os solos com altas concentraçóes desses poluentes. As plantas que crescem nesses solos metalíferos podem apresentar modificaçôes morfofisiológicas e anatômicas, mas os efeitos tóxicos do metal na planta dependem de sua tolerância para cada elemento químico (PORTO, 1986).

Os resultados aqui encontrados reportam que $\mathrm{o} \mathrm{Pb}$ não interferiu no volume da semente de S. terebinthifolius durante os dias que antecederam a emergência da radícula.

A S. terebinthifolius teve seu desenvolvimento germinativo afetado pelo $\mathrm{Pb}$, mas mostrou-se tolerante a condiçôes de estresse químico provocado pela maior concentração de $\mathrm{Pb}$. Esse comportamento foi também reportado por PEREIRA et al. (2013b) para a espécie $S$. molle.

A reidrataçáo das sementes por meio da pré-embebição em água tem a função de prepará-las para a semeadura, de maneira que intensifica as atividades metabólicas, desencadeando o crescimento do eixo embrionário; além disso, o processo de germinação se inicia e se acelera à medida que as sementes são postas para embeber em água (SANTOS, 2007).

Apesar do $\mathrm{Pb}$ interferir no percentual germinativo e no IVG de $S$. terebinthifolius já na concentração $0,2 \mathrm{mM}$ e $0,4 \mathrm{mM}$, respectivamente, resultados similares na redução do G\% foram reportados por PEREIRA et al. (2013b) na germinaçáo de sementes de $S$. molle submetidas às concentraçóes de 0,5 a $5,0 \mathrm{mM}$ de $\mathrm{Pb}$, provocando a reduçáo do $\mathrm{G} \%$ a partir de $0,5 \mathrm{mM}$ de $\mathrm{Pb}$ e a redução significativa do crescimento das partes aéreas e das raízes das plântulas.

$\mathrm{O} \mathrm{Pb}$ é absorvido pelas raízes, provocando diversas alteraçôes morfológicas, fisiológicas e bioquímicas, tais como: inibição da germinação de sementes (RIBEIRO et al., 2015), redução do crescimento das raízes ou de toda a planta, clorose foliar, modificaçôes nas atividades enzimáticas e na fotossíntese (PEREIRA et al., 2013a). Além disso, ele pode provocar mudanças na permeabilidade e na composiçáo da membrana 
celular e alteraçóes em atividades enzimáticas (WÓJCIK; TUKIENDORF, 2014). germinativa também reduzida significativamente. Entretanto, esses efeitos não foram elevados quando a $S$. terebinthifolius foi exposta a concentraçóes maiores de $\mathrm{Pb}$.

\section{CONCLUSÃO}

Os efeitos tóxicos do $\mathrm{Pb}$ sobre as sementes e as plântulas de S. terebinthifolius foram observados a partir da concentração de $0,2 \mathrm{mM}$ de $\mathrm{Pb}$, com a inibição do desenvolvimento germinativo; e aquelas expostas a $0,4 \mathrm{mM}$ de $\mathrm{Pb}$ têm sua velocidade

\section{AGRADECIMENTOS}

Ao Conselho Nacional de Desenvolvimento Científico e Tecnológico (CNPq), pelo apoio para desenvolver este trabalho de pesquisa.

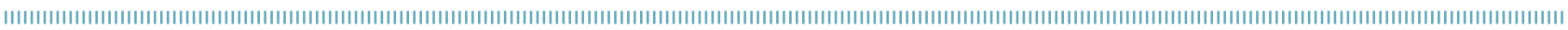
REFERÊNCIAS

AGENCY FOR TOXIC SUBSTANCES \& DISEASE REGISTRY (ATSDR). U.S. Department of Health and Human Services. Toxicological profile for lead. Atlanta: ATSDR, 2008. Disponível em: <http:// www.atsdr.cdc.gov/cercla/05list.html>. Acesso em: 8 fev. 2014.

BORGES, K.S.C.; D'AVILA, R.C.; CAMPOS, M.L.; COELHO, C.M.M.; MIQUELLUTI, D.J.; GALVAN, N.D.S. Germinação e desenvolvimento inicial da Brachiaria brizantha e Brachiaria decumbens em exposição de cádmio, chumbo e cobre. Journal of Seed Science, v.38, n.4, 2016.

BRASIL. Ministério da Agricultura, Pecuária e Abastecimento. Secretaria de Defesa Agropecuária. Regras para análise de sementes. Brasília: MAPA/ACS, 2009. 395p. Disponível em: <http:// www.agricultura.gov.br/arq_editor/file/Laborat\%C3\%B3rio/ Sementes/Regras\%20para\%20Analise\%20de\%20Sementes. pdf $>$. Acesso em: 8 fev. 2014.

FIRATLIGIL-DURMUŞ, E.; ŠÁRKA, E.; BUBNÍK, Z.; SCHEJBAL, M.; KADLEC, P. Size properties of legume seeds of different varieties using image analysis. Journal of Food Engineering, Warszawa, v.99, n.4, p.445-451, 2010.

GOMES, F.S.; PROCÓPIO, T.F.; NAPOLEÃO, T.H.; COELHO, L.C.B.B.; PAIVA, P.M.G. Antimicrobial lectin from Schinus terebinthifolius leaf. Journal of Applied Microbiology, v. 1 14, n.3, p.672-679, 2013 a.

GOMES, L.J.; SILVA-MANN, R.; MATTOS, P.P.; RABBANI, A.R.C. Pensando a biodiversidade: aroeira (Schinus terebinthifolius RADDI). São Cristóvão: Editora UFS, 2013 b. 372 p. (Embrapa Florestas Livros Científicos).

GORDIN, C.R.B.; MARQUES, R.F.; MASETTO, T.E.; SCALON, S.D.P.Q. Germinação, biometria de sementes e morfologia de plântulas de Guizotia abyssinica Cass. Journal of Seed Science, Londrina, v.34, n.4, 2012.

MAGUIRE, J.D. Speed of germination-aid in selection and evaluation for seedling emergence and vigor. Crop Science, Madison, v.2, n.2, p.176-177, 1962.

MCCABE, W.L.; SMITH, J.C.; HARRIOTT, P. Unit operations of chemical engineering. New York: McGraw-Hill, 1993. 324p.
MISHRA, A.; CHOUDHURI, M.A. Amelioration of lead and mercury effects on germination and rice seedling growth by antioxidants. Biologia Plantarum, Praga, v.41, n.3, p.469-473, 1998.

MOHSENIN, N.N. Physical properties of plant and animal materials. New York: Gordon and Breach Science, 1983. 702p.

MORAIS, W.W.C.; SUSIN, F.; VIVIAN, M.A.; ARAÚJO, M.M. Influência da irrigação no crescimento de mudas de Schinus terebinthifolius. Pesquisa Florestal Brasileira, v.32, n.69, p.23, 2012.

NASCIMENTO, D.F.D.; LELES, P.S.D.S.; OLIVEIRA NETO, S.N.D.; MOREIRA, R.T.S.; ALONSO, J.M. Crescimento inicial de seis espécies florestais em diferentes espaçamentos. Cerne, Lavras, v.18, n.1, p.159-165, 2012.

OLIVEIRA JUNIOR, L.F.G.; SANTOS, R.B.; REIS, F.O.; MATSUMOTO, S.T.; BISPO, W.M.S.; MACHADO, L.P.; OLIVEIRA, L.F.M. Fungitoxic effect of essential oil from aroeira (Schinus terebinthifolius RADDI) on Colletotrichum gloeosporioides. Revista Brasileira de Plantas Medicinais, v.15, n.1, p.150-157, 2013.

PACHECO, M.V.; SILVA, C.S.D.; SILVEIRA, T.M.T.; HÖLBIG, L.D.S.; HARTER, F.S.; VILLELA, F.A. Physiological quality evaluation of the radii Schinus terebinthifolius seeds. Revista Brasileira de Sementes, Londrina, v.33, n.4, p.762-767, 2011.

PEREIRA, F.J. Características anatômicas e fisiológicas de aguapée índice de fitorremediação de alface d'água cultivados na presença de arsênio, cádmio e chumbo. $116 \mathrm{p}$. Tese (Doutorado em Agronomia Fisiologia Vegetal) - Universidade Federal de Lavras, Lavras, 2010.

PEREIRA, M.P.; PEREIRA, F.J.; ALMEIDA RODRIGUES, L.C.; BARBOSA, S.; CASTRO, E.M. Fitotoxicidade do chumbo na germinação e crescimento inicial de alface em função da anatomia radicular e ciclo celular. Revista Agro@ mbiente On-line, v.7, n.1, p.36-43, 2013a.

PEREIRA, M.P.; PEREIRA, F.J.; CORRÊA, F.F.; OLIVEIRA, C.; CASTRO, E.M.; BARBOSA, S. Lead tolerance during germination and early growth of the Brazilian peppertree and the morphophysiological modifications. Revista de Ciências Agrárias, Recife, v.56, p.72-79, $2013 \mathrm{~b}$. 
PORTO, M.L. Vegetação metalófila e o desenvolvimento mineral. In: SIMPÓSIO DO TRÓPICO ÚMIDO, 1., 1986. Anais... Belém, 1986.

RIBEIRO, E.S.; PEREIRA, M.P.; CASTRO, E.M.; BARONI, G.R.; CORRÊA, F.F.; PEREIRA, F.J. Relações da anatomia radicular na absorção, no acúmulo e na tolerância ao chumbo em Echinodorus grandiflorus. Revista Brasileira de Engenharia Agrícola e Ambiental, v. 19, n.6, 2015.

SAHAY, K.M.; SINGH, K.K. Unit operations of agricultural processing. New Delhi: Vikas, 2004. 386p.

SANTANA, J.S.; SARTORELLI, P.; GUADAGNIN, R.C.; MATSUO, A.L.; FIGUEIREDO, C.R.; SOARES, M.G.; SILVA, A.M.; LAGO, J.H.G. Essential oils from Schinus terebinthifolius leaves-chemical composition and in vitro cytotoxicity evaluation. Pharmaceutical Biology, v.50, n.10, p.1248-1253, 2012.

SANTOS, F.S. Biometria, germinação e qualidade fisiológica de sementes de Tabebuia chrysotricha (Mart. Ex A. DC.) Standl. provenientes de diferentes matrizes. 48f. Dissertação (Mestrado em Agronomia, Produção e Tecnologia de Sementes) - Faculdade de Ciências Agrárias e Veterinárias, Universidade Estadual Paulista “Júlio de Mesquita Filho", Jaboticabal, 2007.

SHARMA, P.; DUBEY, R.S. Lead toxicity in plants. Brazilian Journal of Plant Physiology, Rio de Janeiro, v. 17, n. 1, p.35-52, 2005.

SILVA, E.; GUILHERME, M.F.S.; OLIVEIRA, H.M.; ARAÚJO, L.N.C.P.; VIANA, Z.C.V.; SANTOS, V.L.C.S. Ecotoxicological effects of cadmium on the germination and initial development of Schinus terebinthifolius. Revista de Ciências Agrárias, Lisboa, v.40, n.2, 2017 a.
SILVA, E.; OLIVEIRA, H.M.; ARAÚJO, L.N.C.; GUILHERME, M.F.S.; MARACAJÁ, P.B. Caracterização morfológica e qualidade fisiológica de cultivares de sementes de gergelim. Revista Verde de Agroecologia e Desenvolvimento Sustentável, Pombal, v.9, n.3, p.149-156, 2014

SILVA, E.; SANTOS, P.S.; GUILHERME, M.F.S. Lead in plants: a brief review of its effects, mechanisms toxicological and remediation. Agrarian Academy, Goiânia, v.2, n.3, p.1-20, 2015.

SILVA, R.M.; CARDOSO, A.D.; DUTRA, F.V.; MORAIS, O.M. Aspectos biométricos de frutos e sementes de Caesalpinia ferrea Mart. Ex Tul. provenientes do semiárido baiano. Revista de Agricultura Neotropical, v.4, n.3, p.85-91, 2017b.

SOUZA, D.C.L.; SILVA-MANN, R.; FERREIRA, R.A.; GOMES, L.J.; ALMEIDA, T.D.S.; OLIVEIRA, A.D.S.; GOIS, I.B. Produção de frutos e características morfofisiológicas de Schinus terebinthifolius Raddi. na região do baixo São Francisco, Brasil. Revista Árvore, Viçosa, p.923-932, 2013.

SOUZA, L.A.; ANDRADE, S.A.L.; SOUZA, S.C.R.; SCHIAVINATO, M.A. Tolerância e potencial fitorremediador de Stizolobium aterrimum associada ao fungo micorrízico arbuscular Glomus etunicatum em solo contaminado por chumbo. Revista Brasileira de Ciência do Solo, Viçosa, v.35, p.1441-1451, 2011.

WÓJCIK, M.; TUKIENDORF, A. Accumulation and tolerance of lead in two contrasting ecotypes of Dianthus carthusianorum. Phytochemistry, v.100, p.60-65, 2014. 